\title{
УДК 622.276 \\ ЭКСПЕРИМЕНТАЛЬНОЕ ИССЛЕДОВАНИЕ ВЛИЯНИЯ ЗАБОЙНОГО ДАВЛЕНИЯ ДОБЫВАЮЩИХ СКВАЖИН НА ВЫРАБОТКУ ЗАПАСОВ ИЗ СЛОЖНОПОСТРОЕННЫХ КАРБОНАТНЫХ КОЛЛЕКТОРОВ
}

\author{
Мартюшев Дмитрий Александрович, \\ martyushevd@inbox.ru
}

Пермский национальный исследовательский политехнический университет, Россия, 614990, г. Пермь, пр. Комсомольский, 29.

\begin{abstract}
Актуальность работы обусловлена тем, что при разработке сложнопостроенных карбонатных залежей зачастую возникают сложности, связанные с системой поддержания пластового давления и выбором оптимальных технологий, направленных на эфффективную выработку запасов нефти. В данных условиях для поддержания уровня добычи на рентабельном уровне необходимо оптимизировать забойные давления скважин. Нефтяным компаниям, разрабатывающим карбонатные залежи, стоит обращать внимание на величину оптимального забойного давления, которая обеспечивает наиболее рациональную выработку запасов. Несмотря на то, что данный вопрос рассматривается достаточно долгое время многими отечественными и зарубежными учеными, он на сегодняшний момент времени остается нерешенным и в то же время имеет значительную научную и практическую значимость.

Целью работы является обоснование значения оптимального забойного давления добывающих скважин и его влияния на выработку запасов из сложнопостроенного карбонатного коллектора Гагаринского нефтяного месторождения.

Объект: карбонатная залежь Гагаринского нефтяного месторождения.

Методы: фильтрационные установки с моделированием пластовых условий УИК-5ВГ и AFS-300; использование гидродинамического симулятора Tempest версии 8.3.1 компании Roxar.

Результаты. Смыкание естественных трещин приводит не только к снижению производительности скважин и к неполной выработке запасов нефтти в зоне дренирования, но и к низкой эфффективности применяемых мероприятий, а также к ухудшению гидродинамической связи между скважинами. Следовательно, в данных условиях важным и необходимым является обоснование оптимальных забойных давлений добывающих скважины на начальных этапах разработки карбонатных залежей. Проведенные лабораторные исследования и расчеты с помощью геолого-гидродинамической модели карбонатной залежи, которая учитьвает особенности строения пустотного пространства, показали практическое значение (выражается в увеличение добычи нефти) оптимизации забойного давления добывающих скважин, эксплуатирующих карбонатные трещиноватые коллектора. Проведенный расчет экономической составляющей оптимизации (регулирование величины забойного давления) работы трех добывающих скважин Гагаринского месторождения позволит дополнительно получить 19,5 млн р.
\end{abstract}

\section{Ключевые слова:}

Естественная трещиноватость, геолого-гидродинамическая модель, дебит нефтти, дополнительная добьча нефрти, закачка воды, напряженное состояние горных пород, проницаемость, раскрытость трещин.

\section{Введение}

Проблемы и сложности, возникающие при добыче углеводородного сырья и выборе технологий для эффективной разработки сложнопостроенных карбонатных коллекторов, описываются многими учеными [1-3]. В настоящее время большинство научных методов и технологий для разработки карбонатных залежей используется на практике не в полной мере. Связано это, в первую очередь, со сложившимися традиционными подходами в области разработки терригенных коллекторов, во-вторых, с обширным разнообразием геологических особенностей строения и фильтрационноемкостных свойств карбонатных залежей. Все эти факторы предопределяют и в тот же момент осложняют выбор технологий для разработки и выработки запасов углеводородов из карбонатных коллекторов.

Карбонатные залежи зачастую характеризуются сложным геологическим строением, связанным с различными условиями осадконакопления. Вследствие этого на залежах выделяются литолого-фациальные зоны с различными фильтрационно-емкостными свойствами. Карбонатные объекты характеризуются высокой неоднородностью и расчленённостью коллектора $[4,5]$. Стоить отметить, что, исходя из анали- за опыта разработки, в большинстве случаев закачка в пласт воды является малоэффективной как со стороны поддержания пластового давления (ППД), так и со стороны выработки запасов нефти [6-9]. Значительная неоднородность и сложность геологического строения карбонатных коллекторов оказывают существенное влияние (в некоторых случаях полностью отсутствует) на гидродинамическое взаимодействие между нагнетательными и добывающими скважинами [2, 10-14].

Еще одной актуальной проблемой при разработке данного типа коллектора является значительное влияние снижения пластового и забойного давлений ниже давления насыщения на работу залежей, которое изучалось на значительном числе нефтяных месторождений: Самотлорском (В.В. Исайчевым, В.А. Казаковым), Ромашкинском (3.С. Алиевым, Р.Ф. Сагдиевым, Б.Е. Сомовым, Р.Н. Дияшевым, В.Д. Лысенко и др.), Троельжанском и Ярино-Каменноложском (В.Д. Викториным, Н.Е. Стадниковой), Ерсубайкинском, Ямашинском (Н.Г. Зайнуллиным, Р.Н. Дияшевым и др.). Основные выводы исследований сводились к следующему: снижение забойного и пластового давлений приводит к значительному уменьшению 
проницаемости по нефти. При этом коэффициенты продуктивности скважин уменьшаются в два и более раза. Такой же эффект наблюдается не только на российских месторождениях, но и на месторождениях Канады, Венесуэлы и США [15-19].

Как правило, для увеличения добычи из сложнопостроенных карбонатных коллекторов нефтяные компании стремятся устанавливать оптимальные (рациональные) забойные давления для добывающих скважин. Многими учеными [20-24] в области разработки карбонатных коллекторов отмечается, что эксплуатация залежей делится на четыре зоны:

1) $\mathrm{P}_{\text {заб }}>\mathrm{P}_{\text {нас }}-$ область щадящей эксплуатации пласта;

2) $\mathrm{P}_{\text {рац }}<\mathrm{P}_{\text {заб }}<\mathrm{P}_{\text {нас }}-$ область рациональной эксплуатации пласта;

3) $\mathrm{P}_{\text {заб.кр }}<\mathrm{P}_{\text {заб }}<\mathrm{P}_{\text {рац }}-$ область максимальной добычи нефти из пласта;

4) $\mathrm{P}_{\text {заб }}<\mathrm{P}_{\text {заб.кр }}$ - область недопустимой эксплуатации.

Стоить отметить, что нефтяным компаниям, разрабатывающим карбонатные залежи, стоить обращать внимание на величину оптимального забойного давления, которая обеспечивает наиболее рациональную выработку запасов, а не на критическую величину забойного давления. Несмотря на то, что данный вопрос рассматривается достаточно долгое время многими отечественными и зарубежными учеными, он на сегодняшний момент времени остается нерешенным и в то же время имеет значительную научную и практическую значимость

Таким образом, при разработке сложнопостроенных карбонатных залежей зачастую возникают сложности, связанные с работой системы ППД и выбором оптимальных технологий выработки запасов нефти. В данных условиях для поддержания уровня добычи на рентабельном уровне необходимо оптимизировать забойные давления скважин. Для обоснования оптимальных забойных давлений добывающих скважин и их влияния на выработку запасов в статье рассматривается карбонатная залежь Гагаринского месторождения (Пермский край).

\section{Общие сведения об объекте исследования}

На рассматриваемом объекте Гагаринского месторождения вследствие неравномерности развития трещиноватости коллекторов выделены четыре литолого-фациальные зоны, каждая из которых требует индивидуального подхода в разработке месторождения [5]. Скважины, расположенные в зоне рифового гребня, характеризуются наиболее высокой производительностью за весь период работы. Скважины, расположенные в зонах верхней и нижней частей тылового шлейфа, характеризуются максимальным темпом снижения производительности.

На объекте наблюдается отрицательная динамика пластового давления. Снижение давления может быть вызвано недостаточной компенсацией темпов отбора и низкой эффективностью системы ППД. В конце 2018 г. на рассматриваемой залежи проводились трассерные исследования с целью изучения гидродинамической связи между нагнетательными и добывающими скважинами, а также влияния закачки на вы- работку запасов. По результатам трассерных исследований установлено, что доля воды, приходящаяся на добывающую скважину, составляет менее $1 \%$, что указывает на слабую гидродинамическую связь между скважинами и на малую эффективность закачки воды на выработку запасов нефти [14].

В связи со значительной неоднородностью коллекторских свойств дебит скважины определяется не столько толщиной пласта, сколько типом коллектора, расчлененностью вскрываемого разреза и принадлежностью к той или иной фациальной зоне. Низкое энергетическое состояние только усугубляет ситуацию и, соответственно, повышает риск неполучения плановых дебитов $[5,8]$.

Таким образом, в результате проведенного детального анализа отмечается существенное влияние естественной трещиноватости на эксплуатацию скважин. Снижение пластового давления обусловлено как недостаточной компенсацией отборов закачкой, так и несоответствием по разрезу интервалов отдачи и приема в добывающих и нагнетательных скважинах. В данных условиях поддержание добычи на плановом уровне возможно за счет оптимизации забойного (определение оптимального) давления добывающих скважин.

Для обоснования оптимальных (рациональных) забойных давлений добывающих скважин проведены лабораторные исследования на образцах керна с целью оценки изменения проницаемости коллектора при динамике эффективного давления, которые в дальнейшем сопоставлены с результатами эксплуатации скважин.

\section{Результаты проведения лабораторных исследований}

Современные программные продукты гидродинамического моделирования используют исходные данные в форме таблиц изменения фильтрационноемкостных свойств пластовых систем с изменением давления. Как правило, изменение пористости происходит через линейную функцию, в то же время проницаемость коллектора принимается постоянной величиной. Для создания полной и приближенной к пластовым условиям картины необходимо в геологогидродинамических моделях наиболее полно учитывать динамику фильтрационных свойств коллектора, а для этого необходимо проведение специальных лабораторных исследований на керновом материале.

С использованием керновых моделей проведена серия лабораторных исследований, основанная на изучении динамики проницаемости горной породы при создании различных давлений. При оценке влияния напряженного состояния на фильтрационноемкостные свойства горных пород использовалась установка УИК-5ВГ. В кернодержателе фильтрационной установки на образцы керна создавалось условие одновременного воздействия внутрипорового давления $\left(\mathrm{P}_{\text {пор }}\right)$ и давления обжима $\left(\mathrm{P}_{\text {обж }}\right)$. В экспериментах нагрузка образца обеспечивалась до необходимого эффективного давления путем создания депрессии давлений: $\mathrm{P}_{э ф}=\mathrm{P}_{\text {обж}}-\mathrm{P}_{\text {пор }}$. По результатам проведения лабораторных исследований построена зави- 
симость коэффициента абсолютной проницаемости от изменения эффективного давления (использовались образцы керна, которые относятся к трещинному типу коллектора, и образцы, характеризующиеся поровым строение пустотного пространства).

Стоить отметить, что для образцов керна порового типа даже при $\mathrm{P}_{\text {эф}}=35$ МПа снижение значения проницаемости минимально и не превышает $3 \%$ от начального значения. В целом для 93 \% исследованных образцов характерна стабильность величин коэффициента пористости и проницаемости при росте $\mathrm{P}_{\text {эф }}$ (в 37 случаях из 40). Для трещиноватых образцов керна, напротив, при создании нагрузки уже в диапазоне до 5 МПа установлено резкое снижение коэффициента пористости и проницаемости; относительное снижение фильтрационно-емкостных свойств при этом составляет $90 \%$.

В ряде экспериментов динамика коэффициента пористости и проницаемости от созданного эффективного давления исследована первоначально с ростом нагрузки на образец керна (от 0 до 35 МПа), а затем с последовательным ее уменьшением до $\mathrm{P}_{э ф}=0$.

Для образцов керна порового типа эксперименты показали практически полное восстановление фильтрационно-емкостных свойств после снижения нагрузки. Принципиально иная ситуация установлена для трещиноватых образцов керна, емкостное пространство которых по данным томографических исследований выполнено вторичными пустотами, преимущественно трещинами и мелкими порами, связанными с выщелачиваем детрита и оолитами. В данном случае после роста $\mathrm{P}_{\text {эф }}$ от 0 до 35 МПа и последующего его снижения вследствие смыкания трещин фильтрационно-емкостные свойства в полной мере не восстанавливаются.

По результатам опытов также установлено, что при создании нагрузки, равной 4 МПа, относительное изменение проницаемости для трещиноватых образцов составляет в среднем 78 \%. Тогда как для образцов керна порового типа при $\mathrm{P}_{э ф}=4$ МПа проницаемость снижается менее чем на $1 \%$. Очевидно, что примеры резкого ухудшения фильтрационноемкостных свойств трещиноватых коллекторов при нагрузке и их неполное восстановление после ее снятия является следствием смыкания трещин при росте $\mathrm{P}_{э ф}$. Существенное снижение проницаемости наблюдается в интервале давлений от 0 до 6 МПа. Более подробное и детальное описание методики проведения исследования и полученных результатов представлено в работе [25].

Таким образом, проанализированная в работе серия опытов позволила установить, что в карбонатных коллекторах, характеризующихся трещиноватостью, при снижении нагрузки проницаемость коллектора в полной мере не восстанавливается. Соответственно на участках развития трещиноватых коллекторов с самого начала эксплуатации скважин рекомендуется значительно не снижать их забойные давления.

\section{Анализ режимов работы добывающих скважин}

Сравним достоверность результатов, полученных в лабораторных условиях, с динамикой эксплуатации скважины, которая расположена в зоне верхнего тылового шлейфа. Эксплуатация данной скважины сопровождалась регулированием (изменением) забойного давления (рис. 1).

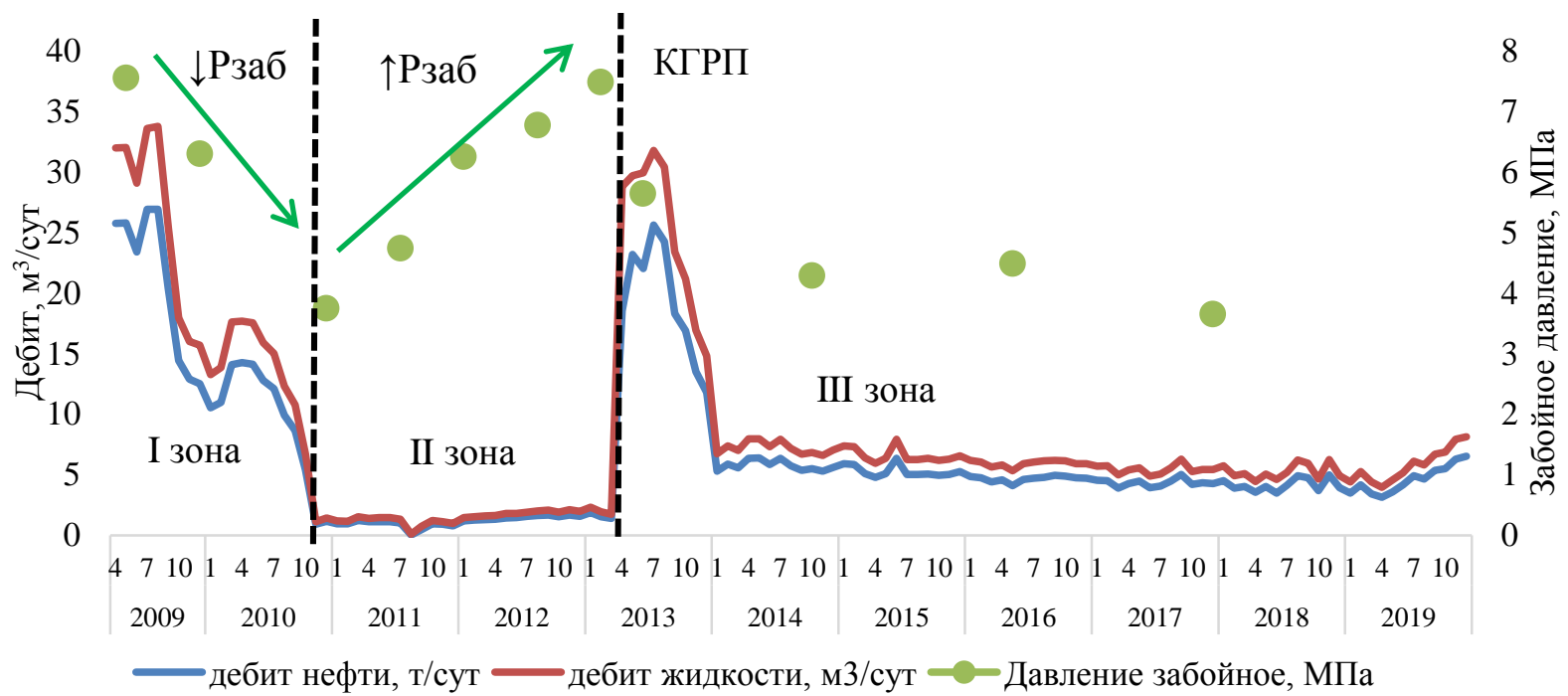

Рис. 1. Динамика технологических показателей работы скважины, расположенной в зоне верхнего тылового шлейфа Fig. 1. Dynamics of technological indicators of the well located in the zone of the upper rear loop

Скважина начала работу в апреле 2009 г. с дебитом по нефти 25,8 т/сут. Первое гидродинамическое исследование (ГДИ) (забойное давление 7,6 МПа, пластовое 12,8 МПа), при интерпретации которого получен коэффициент проницаемости равный 0,0260 мкм², проведено 15.05.2009. За период эксплу- атации скважины проведено 11 гидродинамических исследований. В табл. 1 представлены результаты интерпретации данных гидродинамических исследований, которые позволили оценить динамику проницаемости и средней раскрытости естественных трещин при изменении забойного давления. 
Таблица 1. Результаты интерпретации данных гидродинамических исследований

Table 1. Results of interpretation of data from well tests

\begin{tabular}{|c|c|c|c|c|c|}
\hline $\begin{array}{l}\text { Дата } \\
\text { Date }\end{array}$ & $\begin{array}{c}\text { Давление забой- } \\
\text { ное, MПа } \\
\text { Bottomhole } \\
\text { pressure, MPa }\end{array}$ & 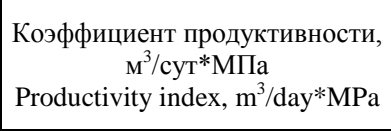 & $\begin{array}{c}\text { Давление пласто- } \\
\text { вое, МПа } \\
\text { Reservoir pressure, } \\
\text { MPa }\end{array}$ & $\begin{array}{l}\text { Проницаемость, } \\
\text { мкм }^{2} \\
\text { Permeability, } \mu^{2}\end{array}$ & $\begin{array}{c}\text { Раскрытость естественных } \\
\text { трещин, мкм* } \\
\text { Openness natural fractures, um } \\
*\end{array}$ \\
\hline 15.05 .2009 & 7,554 & 6,24 & 12,686 & 0,0260 & 55,7 \\
\hline \begin{tabular}{|l|}
19.12 .2009 \\
\end{tabular} & 6,298 & 5,71 & 9,049 & 0,0152 & 37,1 \\
\hline 24.12 .2010 & 3,747 & 0,49 & 6,403 & 0,0139 & 7,9 \\
\hline 06.07.2011 & 4,738 & 0,54 & 7,691 & 0,0037 & 4,1 \\
\hline 06.01.2012 & 6,249 & 0,64 & 8,744 & 0,0028 & 2,1 \\
\hline \begin{tabular}{|l|}
09.08 .2012 \\
\end{tabular} & 6,769 & 0,79 & 9,163 & 0,0021 & 2,1 \\
\hline 21.02 .2013 & 7,485 & 1,25 & 9,010 & 0,0020 & - *** \\
\hline \begin{tabular}{|l|}
17.06 .2013 \\
\end{tabular} & 5,641 & 8,08 & 9,241 & 0,0143 & 15,4 \\
\hline 24.10 .2014 & 4,287 & 1,66 & 7,779 & 0,0034 & 5,4 \\
\hline 21.05 .2016 & 4,483 & 1,32 & 8,927 & 0,0010 & - \\
\hline \begin{tabular}{|l|}
09.12 .2017 \\
\end{tabular} & 3,649 & 1,29 & 7,834 & 0,0011 & - \\
\hline
\end{tabular}

*Средняя раскрытость естественных трещин определялась при обработке гидродинамических исследований методом Уоррена-Pyma/Average opening of natural fractures was determined during the processing of hydrodynamic studies by the Warren-Root method

**По данным гидродинамических исследований естественная трещчиноватость не идентифииируется/According to hydrodynamic studies, natural fracturing is not identified.

По результатам анализа эксплуатации скважины выделено три зоны:

- I - работа скважины при снижении забойного давления;

- II - работа скважины при увеличении забойного давления;

- III - работа скважины после проведения кислотного гидравлического разрыва пласта (КГРП).

На первом участке работы скважины наблюдается интенсивное падение дебита нефти с 25,8 т/сут (01.04.2009) до 5,4 т/сут (01.10.2010). Забойное давление за данный период снизилось в два раза (на $3,8 \mathrm{MПа),} \mathrm{при} \mathrm{этом} \mathrm{проницаемость} \mathrm{пласта} \mathrm{снизилась} \mathrm{в}$ 1,9 раз с 0,0260 до 0,0139 мкм $^{2}$.

На втором участке работы скважины наблюдается увеличение забойного давления до первоначального уровня с 3,7 до 7,5 МПа, при этом дебит нефти изменялся незначительно и держался на уровне 1,1 т/сут. Коэффициент проницаемости снизился в семь раз - с 0,0139 до 0,0020 мкм² $^{2}$.

Таким образом, проницаемость пласта уменьшилась в 13 раз (при первоначальном забойном давлении 7,6 МПа проницаемость пласта составляла 0,0260 мкм $^{2}$ (15.05.2009), при восстановлении забойного давления до 7,5 МПа (21.02.2013) проницаемость составила 0,0020 мкм $^{2}$ ).

На третьем участке эксплуатации скважины проведен КГРП, что позволило восстановить проницаемость до 0,0143 мкм $^{2}$ и дебит нефти до 25 т/сут. Эффект от проведенного КГРП продлился всего шесть месяцев, дебит снизился до величины 5,5 т/сут. Забойное давление снизилось с 5,6 до 3,6 МПа, проницаемость вновь уменьшилась с 0,0143 до 0,0011 мкм² $^{2}$.

Исходя из графика эксплуатации скважины (рис. 1) и результатов интерпретации ГДИ (табл. 1), можно сделать вывод о том, что падение забойного давления привело к существенному снижению проницаемости пласта. При повышении забойного давления прони- цаемость пласта не восстанавливается до исходных значений. Полученные результаты подтверждаются результатами фильтрационных исследований.

Изменение (снижение) забойного давления в скважинах приводит к деформационным процессам в пласте (смыкание естественных трещин) и, как следствие, к существенному снижению продуктивности и производительности [15]. Последующее увеличение забойного давления не восстанавливает в полной мере проницаемость, что негативно влияет на производительность и полноту выработки запасов нефти [18-20].

Необходимо отметить, что смыкание естественных трещин приводит не только к снижению производительности скважин и неполной выработке запасов нефти в зоне дренирования, но и к низкой эффективности применяемых мероприятий, а также к ухудшению гидродинамической связи между скважинами, следовательно, в данных условиях важным и необходимым является обоснование оптимальных забойных давлений добывающих скважины на начальных этапах разработки карбонатных залежей.

Для обоснования оптимальных забойных давлений скважин и интенсификации добычи нефти целесообразно выбирать скважины, район дренирования которых обладает наибольшими остаточными извлекаемыми запасами. Извлекаемые запасы нефти для каждой скважины анализируемой залежи посчитаны с помощью геолого-гидродинамической модели (ГГДМ) в ПО ResVIEW при сопоставлении текущих дебитов нефти с остаточными извлекаемыми запасами. Также необходимо учитывать текущее пластовое и забойные давления в зонах дренирования скважин. По результатам проведенного анализа выделены три скважины: 431, 432 и 433.

Для определения оптимального забойного давления для выделенных скважин в ГГДМ необходимо изменять значения забойного давления на $1 \mathrm{MПа/год.}$ Необходимые расчеты выполнялись в гидродинами- 
ческом симуляторе Tempest версии 8.3.1 компании Roxar с помощью регулирования забойного давления и проницаемости [26-29].

По результатам лабораторных исследований и промыслового анализа эксплуатации скважин построена зависимость $k_{\text {прон }}-\Delta P$, которая позволяет оценить значение проницаемости при изменении забойного и/или пластового давлений. Для настройки геолого-гидродинамической модели для учета изменения проницаемости коллектора от динамики давлений использовался один из методов, описанных в работе [30], который дает удовлетворительные показатели при рациональных временных затратах. Предварительно проницаемость численно настраивалась по результатам интерпретации гидродинамических исследований. Далее происходил процесс модификации гидродинамической модели путем поиска множителей проницаемости в несколько этапов:

1. Преобразование полученной зависимости проницаемости от отношения текущего забойного к начальному пластовому давлению в зависимость проницаемости от текущего пластового давления. Зависимость будет иметь примерно такой же вид.

2. Построение зависимости проницаемости от пластового давления. Проницаемость, получаемая при исследованиях, будет равна проницаемости по латерали $\mathrm{K}_{\mathrm{x}}=\mathrm{K}_{\mathrm{y}}$.

3. Рассчет значения проницаемости по латерали при достаточно маленьком шаге, например, 5 бар, от атмосферного до пластового давления (выше можно уменьшать дискретность).

4. Подстановка горизонтальной проницаемости в зависимость пункта 1. Получается распределение вертикальной проницаемости от пластового давления.

Принимается, что при начальном пластовом давлении проницаемости не изменены, а при изменении давления в ту или иную сторону увеличиваются либо уменьшаются. Так как распределение проницаемости в зоне каждой скважины может значительно различаться, то для использования необходимы не сами значения проницаемостей, а их множители (при $\mathrm{P}_{\text {пл }}=\mathrm{P}_{\text {пл·нач }}$ множитель равен единице).

Установлено, что при значительном снижении пластового давления роль вертикальной фильтрации выходит на первый план. Данная процедура была выполнена для каждой литолого-фациальной зоны рассматриваемого объекта разработки. Таким образом, имеются зависимости изменения проницаемостей по латерали и вертикали для каждой зоны. В отличие от распространенного способа при помощи ключевого слова KVSP применение ключевых слов KVPX, KVPY и KVPZ дает возможность разнонаправленного распределения изменения проницаемости от давления, что и было сделано.

В расчетах использовалась геологогидродинамическая модель карбонатной залежи Гагаринского месторождения, в которой произведен учет трещиноватости и параметра анизотропии проницаемости [31-33]. Особенности создания и использования модифицированной геолого-гидродинамической модели описаны в работе [34].

\section{Результаты гидродинамического}

\section{моделирования работы скважин}

Исходя из динамики дебита нефти в зависимости от изменения забойного давления для скважины 431 установлено, что при значении забойного давления до 6 МПа наблюдается интенсивное снижение дебита нефти. Только при снижении забойного давления до 5 МПа и ниже наблюдается увеличение дебита нефти. Наибольшая накопленная добыча нефти для скважины 431 наблюдается при значении забойного давления 3 МПа, но при этом происходит интенсивное снижение пластового давления по сравнению с вариантом, где забойное давление составляет 8 МПа. Слишком низкое забойное давление приведет к резкому увеличению газового фактора. Исходя из вышесказанного, самым оптимальным вариантом будет поддержание забойного давления на уровне 8 МПа, при этом накопленная добыча составит 67,6 тыс. м³. Наименее эффективным вариантом эксплуатации для данной скважины будет являться величина забойного давления $6 \mathrm{MПа}\left(\mathrm{Q}_{\text {нак }}=66,3\right.$ тыс. $\left.\mathrm{m}^{3}\right)$.

Аналогичная ситуация наблюдается на скважине 432. Наибольшая накопленная добыча нефти будет при значении забойного давления 3 МПа, накопленная добыча составит 135,3 тыс. м³ ${ }^{3}$. Наименее эффективным вариантом эксплуатации для данной скважины будет являться величина забойного давления $5 \mathrm{MПа}\left(\mathrm{Q}_{\text {нак }}=125,6\right.$ тыс. м $\left.{ }^{3}\right)$.

Существенно отличается динамика работы скважины 434 (рис. 2, 3). По результатам гидродинамического моделирования наблюдается снижение дебитов нефти при уменьшении забойного давления. Падение дебита нефти происходит более низкими темпами при забойном давлении $6 \mathrm{MПа}\left(\mathrm{Q}_{\text {нак }}=22,5\right.$ тыс. $\left.{ }^{3}\right)$. Наименее эффективный вариант для данной скважины наблюдается при поддержании забойного давления на уровне $3 \mathrm{MПа}\left(\mathrm{Q}_{\text {нак }}=20,0\right.$ тыс. м $\left.^{3}\right)$.

\section{Экономическая эффективность предлагаемых мероприятий}

Оценка экономической эффективности проводилась с помощью расчета чистого дисконтированного дохода (ЧДД) для каждой отдельной скважины. Исходные данные для расчета экономической эффективности предлагаемых мероприятий представлены в табл. 2.

Наибольший ЧДД (210,3 млн р.) для скважины 431 наблюдается при значении забойного давления 8 МПа. Несмотря на большую добычу нефти при варианте забойного давления 3 МПа ЧДД достигает всего 208,4 млн р. Наименьший ЧДД=203,2 млн р. наблюдается при величине забойного давления 6 МПа. Таким образом, разница между оптимальным и наименее эффективным вариантом принесет прибыль в 7,1 млн р. за счет оптимизации режима работы добывающей скважины.

Наибольший ЧДД (468,7 млн р.) для скважины 432 наблюдается при значении забойного давления 3 МПа. При данном варианте наблюдается наибольшая добыча нефти. Но с технологической точки зрения такое низкое забойное давление приведет к еще 
большему росту газового фактора и рискам прекращения добычи нефти из скважины. Поэтому для оптимального варианта разработки необходимо поддерживать забойное давление на уровне 6 МПа
(ЧДД=460,4 млн р.). Таким образом, разница между оптимальным и наименее эффективным вариантом составит 4,7 млн р. за счет оптимизации режима работы добывающей скважины.

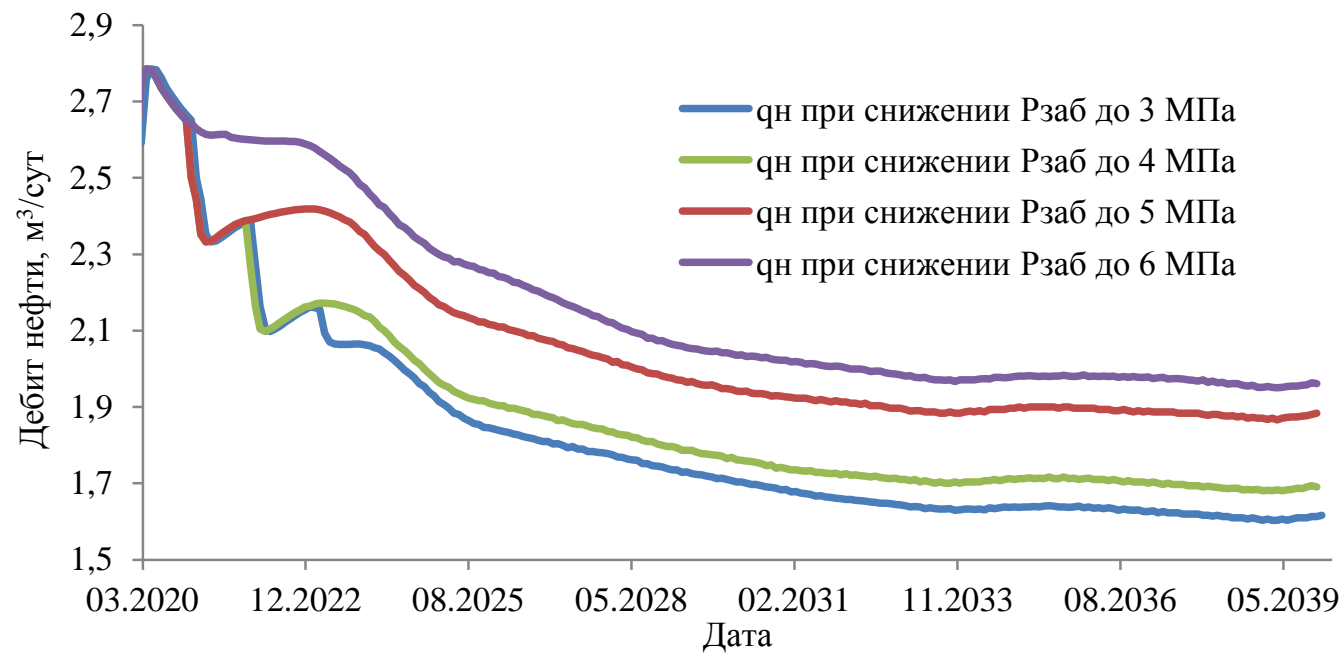

Pис. 2. Динамика дебита нефти скважины 434 в зависимости от изменения забойного давления Fig. 2. Oil production dynamics of well 434 depending on changes in bottomhole pressure

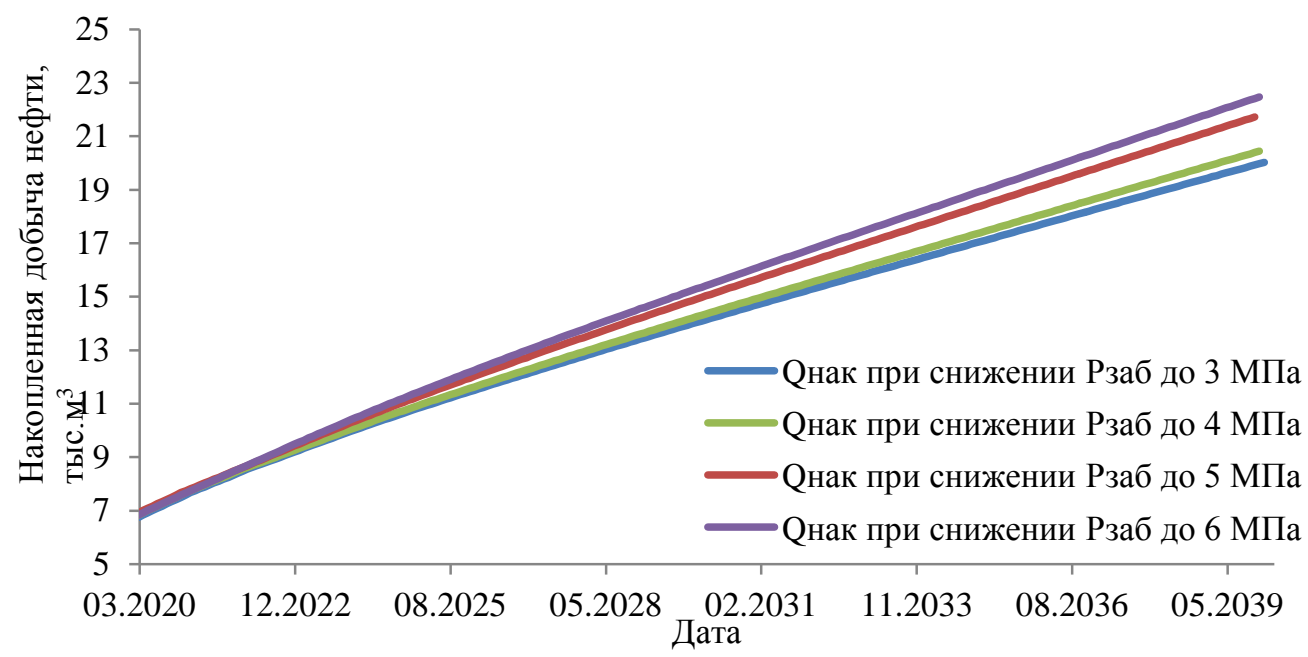

Pис. 3. Динамика накопленной добычи нефти скважины 434 в зависимости от изменения забойного давления Fig. 3. Dynamics of cumulative oil production of well 434 depending on changes in bottomhole pressure

Таблица 2. Исходные данные для расчет чистого дисконтированного дохода

Table 2. Initial data for calculating net present value (NPV)

\begin{tabular}{|c|c|c|c|}
\hline & $\begin{array}{l}\text { Показатели } \\
\text { Indicators }\end{array}$ & $\begin{array}{l}\text { Единицы измерения } \\
\text { Units of measurement }\end{array}$ & $\begin{array}{l}\text { Значение } \\
\text { Value }\end{array}$ \\
\hline $\begin{array}{l}\text { Период } \\
\text { Calculati }\end{array}$ & & $\begin{array}{c}\text { лет } \\
\text { years }\end{array}$ & 20 \\
\hline $\begin{array}{l}\text { Цена на } \\
\text { Urals oil }\end{array}$ & $\begin{array}{l}\text { овые) на } 01.01 .2020 \\
\text { f } 01.01 .2020\end{array}$ & $\begin{array}{l}\text { долл./барр. } \\
\text { dollars/barrel }\end{array}$ & 61,67 \\
\hline & $\begin{array}{l}\text { На добавленную стоимость (НДС) } \\
\text { Added value }\end{array}$ & $\%$ & 20 \\
\hline $\begin{array}{l}\text { Налоги } \\
\text { Taxes }\end{array}$ & $\begin{array}{l}\text { На прибыль } \\
\text { At a profit }\end{array}$ & $\%$ & 20 \\
\hline & $\begin{array}{l}\text { На добычу полезных ископаемых (базовая ставка) } \\
\text { For mining (base rate) }\end{array}$ & $\begin{array}{c}\mathrm{p} . / \mathrm{T} \\
\mathrm{rub} . / \mathrm{t}\end{array}$ & 10172 \\
\hline $\begin{array}{l}\text { Курс до. } \\
\text { The dolla }\end{array}$ & & $\begin{array}{l}\text { рублей за доллар США } \\
\text { rubles per US dollar }\end{array}$ & 61,9 \\
\hline $\begin{array}{l}\text { Цена pe } \\
\text { Oil sales }\end{array}$ & & $\begin{array}{c}\mathrm{p} . / \mathrm{T} \\
\mathrm{rub} . / \mathrm{t}\end{array}$ & 24801 \\
\hline
\end{tabular}


Для скважины 434 (рис. 4) наибольший ЧДД (58,8 млн р.) соответствует наибольшей добыче нефти при величине забойного давления 6 МПа. Разница между оптимальным и наименее эффективным вариантом составляет 7,7 млн р.
Таким образом, проведенный расчет экономической целесообразности оптимизации (регулирование величины забойного давления) работы трех добывающих скважин Гагаринского месторождения позволит дополнительно получить 19,5 млн р.

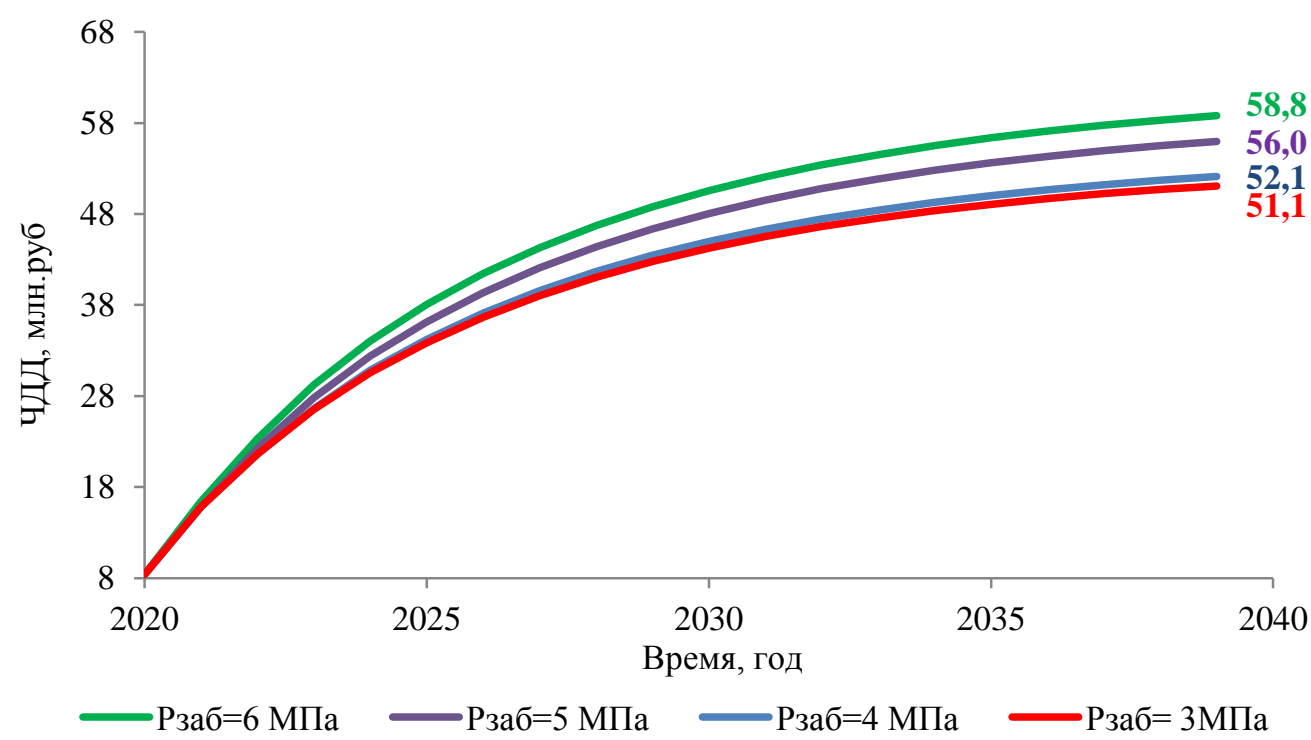

Pис. 4. Зависимость чистого дисконтированного дохода от величины забойного давления для скважины 434

Fig. 4. Net present value dependence on the value of bottomhole pressure of the well 434

\section{Заключение}

Разнообразие геологических условий залегания карбонатных залежей осложняет выбор технологий выработки запасов нефти. Одним из главных регуляторов эффективности разработки месторождения является забойное давление в добывающих скважинах. Оптимальное забойное давление для скважин с карбонатным типом коллектора позволяет увеличить эффективность разработки за счет оптимизации режима работы добывающих скважин. Необоснованное регулирование (снижение) забойного давления в скважинах может привести к смыканию естественных трещин и, как следствие, к снижению коэффициентов продуктивности и производительности скважин, поэтому необходимо устанавливать максимально допустимую продолжительность оптимального режима работы скважины, при котором не проявляется гистерезис коэффициента продуктивности $[35,36]$.

Проведенная серия экспериментов на образцах керна позволила установить, что для трещиноватых образцов при увеличении их напряженного состояния (рост $\mathrm{P}_{\text {э }}$ ) происходит резкое снижение фильтрационно-емкостных свойств. В дальнейшем при снижении (или полном снятии) напряженного состояния филь-

\section{СПИСОК ЛИТЕРАТУРЫ}

1. A novel hydro-mechanical coupled analysis for the fractured vuggy carbonate reservoir / F. Zhang, M. An, B. Yan, Y. Wang, Y. Han // Computers and Geotechnics. - 2019. - V. 106. - P. 68-82

2. A fast method of waterflooding performance forecast for largescale thick carbonate reservoir / Yong Li, Qi Zhang, Daigang Wang, Benbio Song, Pengcheng Liu // Journal of Petroleum Science and Engineering. - 2020. - V. 192. - Article 107227. трационно-емкостные свойства трещиноватых коллекторов не восстанавливаются. К схожим выводам приводит анализ работы добывающих скважин. В участках развития процессов трещиноватости для скважин, работавших при низких забойных давлениях, после восстановления давлений текущая трещинная проницаемость оказывается существенно ниже начальной.

Используя геолого-гидродинамическую модель карбонатной залежи, которая учитывает структуру пустотного пространства горных пород, рассчитаны оптимальные забойные давления для добывающих скважин. Оптимизация забойного давления анализируемых скважин позволит дополнительно получить 19,5 млн р.

Таким образом, с самого начала эксплуатации карбонатных залежей, обладающих естественной трещиноватостью, крайне важно установить оптимальное забойное давление добывающих скважин. Определение и регулирование оптимального забойного давления для каждой добывающей скважины возможно с помощью модифицированных геологогидродинамических моделей, которые учитывают сложную структуру пустотного пространства горных пород.

3. Theories and practices of carbonate reservoirs development in China / Yang Li, Zhijiang Kang, Zhaojie Xue, Songqing Zheng // Petroleum Exploration and Development. - 2018. - V. 45. Iss. 4. - P. 712-722.

4. Kaminskaite I., Fisher Q.J., Michie E.A. Microstructure and petrophysical properties of deformation bands in high porosity carbonates // Journal of Structural Geology. - 2019. - V. 119. P. 61-80. 
5. Мартюшев Д.А., Зайцев Р.А. Влияние петрофизических параметров рифогенных карбонатных коллекторов нефтяных месторождений турнейско-фаменских отложений Верхнего Прикамья на продуктивность добывающих скважин // Известия Томского политехнического университета. Инжиниринг георесурсов. - 2019. - Т. 330. - № 11. - С. 77-85.

6. Исследования о наличии гидродинамической связи между терригенным бобриковским и карбонатным турнейским объектами на базе геолого-технологической модели участка месторождения / М.А. Сайфутдинов, И.Н. Хакимзянов, В.Н. Петров, Р.И. Шешдиров, Л.М. Миронова // Георесурсы. 2018. - T. 20. - № 1. - C. 2-8.

7. Сулейманов Б.А., Лятифов Я.А., Велиев Э.Ф. Применение умягченной воды для повышения нефтеотдачи пласта // SOCAR Proceedings. - 2019. - № 1. - C. 19-28.

8. Ali Y. Jirjees, Abdulaziz M. Abdulaziz Influences of uncertainty in well $\log$ petrophysics and fluid properties on well test interpretation: An application in West Al Qurna Oil Field, South Iraq // Egyptian Journal of Petroleum. - 2019. - V. 28. - Iss. 4. - P. 383-392.

9. Мартюшев Д.А., Пономарева И.Н. Исследование особенностей выработки запасов трещинно-поровых коллекторов с использованием данных гидродинамических исследований скважин // Нефтяное хозяйство. - 2017. - № 10. - С. 102-104.

10. Shedid A. Shedid Vertical-horizontal permeability correlations using coring data // Egyptian Journal of Petroleum. - 2019. V. 28. - Iss. 1. - P. 97-101.

11. The effectiveness of flow salinity waterflooding in naturally fractured reservoirs / Faisal Awad Aljuboori, Jang Hyun Lee, Khaled A. Elraies, Kari D. Stephen // Journal of Petroleum Science and Engineering. - 2020. - V. 191. - Article 107167.

12. Introducing approximate well dynamics into production optimization for operations scheduling / E. Otte Hulse, Th. Lima Silva, E. Camponogara, V. Ramos Rosa // Computers and Chemical Engineering. - 2020. - V. 136. - 106773

13. Adaptive modeling of waterflooding process in oil reservoirs / F. Hourfar, B. Moshiri, K. Salahshoor, M. Zaare-Mehrjerdi, P. Pourafshary // Journal of Petroleum Science and Engineering. 2016. - V. 146. - P. 702-713.

14. Пономарева И.Н., Мартюшев Д.А., Черный К.А. Исследование взаимодействия между нагнетательными и добывающими скважинами на основе построения многоуровневых моделей // Известия томского политехнического университета. Инжиниринг георесурсов. - 2021. - Т. 332. - № 2. - С. 116-126.

15. Alexander Davis, Oladoyin Kolawole, Marshall Watson, Chioma Onwumelu Optimal field development and production design for unconventional reservoirs: A case study from Central Sub-Basin, Permian Basin, new Mexico // Petroleum Research. - 2021. V. 6. - Iss.1. - P. 66-76.

16. Гамес Ф. Исследование трещиноватости, моделирование и анализ неопределенностей карбонатного коллектора с включением динамических данных (Ближний Восток) // Георесурсы. - 2018. - Т. 20. - № 3. - С. 154-157.

17. Фархуллин Р.Г., Ханнанов М.Т. Некоторые особенности гидромеханики нефтяных коллекторов с двойной пористостью при дренировании // Георесурсы. - 2006. - № 2 (19). - С. 37-39.

18. Flowing bottomhole pressure prediction for gas wells based on support vector machine and random samples selection / Wei Chen, Qinfeng Di, Feng Ye, Jingnan Zhang, Wenchang Wang // International Journal of Hydrogen Energy. - 2017. - V. 42. Iss. 29. - P. 18333-18342.

19. Sami Nashawi I., Malallah A.H. Well test analysis of finiteconductivity fractured wells producing at constant bottomhole pressure // Journal of Petroleum Science and Engineering. 2007. - V. 57. - Iss. 3-4. - P. 303-320.

20. A new method for early gas kick detection based on the consistencies and differences of bottomhole pressure at two measured points / Hongwei Yang, Jun Li, Gonghui Liu, Chao Wang, Hailong Jiang, Kuidong Luo, Bin Wang // Journal of Petroleum Science and Engineering. - 2019. - V. 176. - P. 1095-1105.
21. Методика определения забойного давления с использованием многомерных моделей / В.И. Галкин, И.Н. Пономарева, И.А. Черных, Е.В. Филиппов, Г.Н. Чумаков // Нефтяное хозяйство. -2019 . - № 1. - С. 40-43,

22. Dongjae Kam, Jichao Han, Akhil Datta-Gupta. Streamline-based history matching of bottomhole pressure and three-phase production data using a multiscale approach // Journal of Petroleum Science and Engineering. - 2017. - V. 154. - P. 217-233.

23. Martyushev D.A., Yurikov A. Evaluation of opening of fractures in the Logovskoye carbonate reservoir, Perm Krai, Russia // Petroleum Research. URL: https://doi.org/10.1016/j.ptlrs. 2020.11.002 (дата обращения 15.03.2021).

24. Jahanandish J., Salimifard B., Jalalifer H. Predicting bottomhole pressure in vertical multiphase flowing wells using artificial neural networks // Journal of Petroleum Science and Engineering. 2011. - V. 75. - Iss. 3-4. - P. 336-342.

25. Мартюшев Д.А. Оценка влияния напряженного состояния горных пород на проницаемость карбонатных коллекторов // Известия томского политехнического университета. Инжиниринг георесурсов. - 2020. - Т. 331. - № 8. - С. 24-33.

26. Концептуальное геологическое моделирование как основа разработки карбонатных залежей на примере месторождения ближневосточного региона / Р.А. Растегаев, В.В. Морозов, С.И. Мельников, С.А. Идрисова, С.В. Мильчаков // Георесурсы. - 2018. - Т. 20. - № 3. - С. 168-171

27. Mingshui Song Reservoir formation conditions and key technologies for exploration and development in Shengtuo oilfield in Bohai Bay Basin // Petroleum Research. - 2020. - V. 5. Iss. 4. - P. 289-303.

28. Попов В.Л., Поднебесных А.В., Пыльник С.В. Определение и характеристика коэффициента связности коллектора геологогидродинамических моделей нефтегазовых залежей // Известия томского политехнического университета. Инжиниринг георесурсов. - 2020. - Т. 331. - № 1. - С. 211-221.

29. Особенности учета анизотропии проницаемости в гидродинамической модели / Р.И. Ермеков, В.П. Меркулов, О.С. Чернова, М.О. Коровин // Записки Горного института. - 2020. T. 243. - C. 299-304.

30. Аббасов Е.М., Агаева Н.А., Керимова Ш.А. Интегральное моделирование работы газовых скважин с учетом деформируемости коллектора пласта // SOCAR Proceedings. - 2019. № 2. - C. 45-52.

31. Huafeng Sun, Sandra Vega, Guo Tao. Analysis of heterogeneity and permeability anisotropy in carbonate rock samples using digital rock physics // Journal of Petroleum Science and Engineering. - 2017. - V. 156. - P. 416-429.

32. Characterization of unique natural gas flow in fracture-vuggy carbonate reservoir: A case study on Dengying carbonate reservoir in China / Xinhui Xie, Hongjiang Lu, Hucheng Deng, Hongzhi Yang, Bailu Teng, Huazhou Andy Li // Journal of Petroleum Science and Engineering. - 2019. - V. 182. - 106243.

33. Porosity and permeability of tight carbonate reservoir rocks in the north of Iraq / F. Rashid, P.W.J. Glover, P. Lorinczi, R. Collier, J. Lawrence // Journal of Petroleum Science and Engineering. 2015. - V. 133. - P. 147-161.

34. Мартюшев Д.А. Совершенствование геолого-гидродинамической модели карбонатного нефтяного объекта путем учета параметра анизотропии проницаемости // Записки Горного института. - 2020. - Т. 243. - № 3. - С. 313-318.

35. Reservoir and lithofacies shale classification based on NMR logging / Hongyan Yu, Zhenliang Wang, Fenggang Wen, Reza Rezaee, Maxim Lebedev, Xiaolong Li, Yihuai Zhang, Stefan Iglauere // Petroleum Research. - 2020. - V. 5. - Iss. 3. - P. 202-209.

36. Hydrocarbon migration in fracture-cave systems of carbonate reservoirs under tectonic stresses: A mechanism study / Chenjun Huang, Geyun Liu, Kaibo Shi, Jinyin Yina, Jinrui Guo, Chongzhi Tao // Petroleum Research. - 2020. - V. 5. - Iss. 2. - P. 124-130.

Поступила 12.04.2021 г.

\section{Информация об авторах}

Мартюшев Д.А., кандидат технических наук, доцент кафедры нефтегазовых технологий Пермского национального исследовательского политехнического университета. 
UDC 622.276

\title{
EXPERIMENTAL STUDY OF THE INFLUENCE OF BOTTOMHOLE PRESSURE OF PRODUCING WELLS ON RESERVE PRODUCTION FROM COMPLICATED CARBONATE RESERVOIRS
}

\author{
Dmitriy A. Martyushev, \\ martyushevd@inbox.ru
}

Perm National Research Polytechnic University, 29, Komsomolskiy avenue, Perm, 614990, Russia

The relevance of the research is caused by the fact that when developing the complex carbonate deposits, the difficulties often arise. They are associated with the operation of the reservoir pressure maintenance system and the choice of optimal technologies for development of oil reserves. Under these conditions, to maintain the production at a profitable level, it is necessary to optimize the bottomhole pressure of the wells. For oil companies developing carbonate deposits, it is worth paying attention to the value of the optimal bottomhole pressure, which ensures the most rational development of reserves, and not critical. Even though this issue has been considered for quite a long time by many domestic and foreign scientists, it remains unresolved now and at the same time it has significant scientific and practical importance.

The main aim of the study is to substantiate the optimal bottomhole pressure of producing wells and its influence on the development of reserves from the complex carbonate reservoir of the Gagarinskoe oil field.

Object: carbonate reservoir of the Gagarinskoe oil field.

Methods: filtration units with reservoir conditions modeling UIK-5VG and AFS-300; using Roxar's Tempest Fluid Dynamic Simulator version 8.3.1.

Results. Closing of natural fractures leads not only to a decrease in well productivity and to incomplete production of oil reserves in the drainage zone, but also to a low efficiency of the measures used, as well as to a deterioration in the hydrodynamic connection between wells. Therefore, under these conditions, it is important and necessary to substantiate the optimal bottomhole pressures of producing wells at the initial stages of the development of carbonate deposits. Laboratory studies and calculations using a geological and hydrodynamic model of a carbonate reservoir, which takes into account the peculiarities of the geological structure, have shown the practical value (expressed in an increase in oil production) of optimizing the bottomhole pressure of producing wells operating fractured carbonate reservoirs. The calculation of the economic component of optimization (regulation of the bottomhole pressure value) of the operation of three production wells of the Gagarinskoe field will additionally receive 19,5 million rubles.

\section{Key words:}

Natural fractures, geological and hydrodynamic model, oil production rate, additional oil production, water injection, stress state of rocks, permeability, fracture opening

\section{REFERENCES}

1. Zhang F., An M., Yan B., Wang Y., Han Y. A novel hydromechanical coupled analysis for the fractured vuggy carbonate reservoir. Computers and Geotechnics, 2019, vol. 106, pp. 68-82.

2. Yong Li, Qi Zhang, Daigang Wang, Benbio Song, Pengcheng Liu. A fast method of waterflooding performance forecast for largescale thick carbonate reservoir. Journal of Petroleum Science and Engineering, 2020, vol. 192, Article 107227.

3. Yang Li, Zhijiang Kang, Zhaojie Xue, Songqing Zheng. Theories and practices of carbonate reservoirs development in China. Petroleum Exploration and Development, 2018, vol. 45, Iss. 4 pp. 712-722.

4. Kaminskaite I., Fisher Q.J., Michie E.A. Microstructure and petrophysical properties of deformation bands in high porosity carbonates. Journal of Structural Geology, 2019, vol. 119, pp. 61-80.

5. Martyushev D.A., Zaitsev R.A. Influence of oil field reef carbonate reservoir petrophysical parameters of tournasianfamennian deposits in upper Kama on well productivity. Bulletin of the Tomsk Polytechnic University. Geo Assets Engineering, 2019, vol. 330, no. 11, pp. 77-85. In Rus.

6. Sayfutdinov M.A., Khakimzyanov I.N., Petrov V.N., Sheshdirov R.I., Mironova L.M. Studies on the presence of a hydrodynamic connection between the terrigenous Bobrikovsky and carbonate Tournaisian objects based on the geological and technological model of the field site. Georesources, 2018, vol. 20, no. 1, pp. 2-8. In Rus.

7. Suleimanov B.A., Latifov Ya.A., Veliev E.F. Application of softened water to enhance oil recovery. SOCAR Proceedings, 2019, no. 1, pp. 19-28. In Rus.

8. Ali Y. Jirjees, Abdulaziz M. Abdulaziz Influences of uncertainty in well log petrophysics and fluid properties on well test interpretation:
An application in West Al Qurna Oil Field, South Iraq. Egyptian Journal of Petroleum, 2019, vol. 28, Iss. 4, pp. 383-392.

9. Martyushev D.A., Ponomareva I.N. Researching features of development of fractured porous reservoirs reserves using welltest data. Oil industry, 2017, no. 10, pp. 102-104. In Rus.

10. Shedid A.Shedid Vertical-horizontal permeability correlations using coring data. Egyptian Journal of Petroleum, 2019, vol. 28, Iss. 1, pp. 97-101.

11. Faisal Awad Aljuboori, Jang Hyun Lee, Khaled A. Elraies, Kari D. Stephen. The effectiveness of flow salinity waterflooding in naturally fractured reservoirs. Journal of Petroleum Science and Engineering, 2020, vol. 191, Article 107167.

12. Otte Hulse E., Lima Silva Th., Camponogara E., Ramos Rosa V. Introducing approximate well dynamics into production optimization for operations scheduling. Computers and Chemical Engineering, 2020, vol. 136, 106773.

13. Hourfar F., Moshiri B., Salahshoor K., Zaare-Mehrjerdi M., Pourafshary P. Adaptive modeling of waterflooding process in oil reservoirs. Journal of Petroleum Science and Engineering, 2016, vol. 146, pp. 702-713

14. Ponomareva I.N., Martyushev D.A., Cherny K.A. Research of interaction between expressive and producing wells based on construction of multilevel models. Bulletin of the Tomsk Polytechnic University, Geo Assets Engineering, 2021, vol. 332, Iss. 2, pp. 116-126. In Rus

15. Alexander Davis, Oladoyin Kolawole, Marshall Watson, Chioma Onwumelu Optimal field development and production design for unconventional reservoirs: A case study from Central Sub-Basin, Permian Basin, new Mexico. Petroleum Research, 2021, vol. 6, Iss. 1, pp. 66-76.

16. Gamez F. Study of fracturing, modeling, and analysis of uncertainties of a carbonate reservoir with the inclusion of 
dynamic data (Middle East). Georesources, 2018, vol. 20, no. 3, pp. 154-157. In Rus.

17. Farkhullin R.G., Hannanov M.T. Some features of the hydromechanics of oil reservoirs with double porosity during drainage. Georesources, 2006, no. 2 (19), pp. 37-39. In Rus.

18. Wei Chen, Qinfeng Di, Feng Ye, Jingnan Zhang, Wenchang Wang. Flowing bottomhole pressure prediction for gas wells based on support vector machine and random samples selection. International Journal of Hydrogen Energy, 2017, vol. 42, Iss. 29, pp. $18333-18342$.

19. Sami Nashawi I., Malallah A.H. Well test analysis of finiteconductivity fractured wells producing at constant bottomhole pressure. Journal of Petroleum Science and Engineering, 2007, vol. 57, Iss. 3-4, pp. 303-320.

20. Hongwei Yang, Jun Li, Gonghui Liu, Chao Wang, Hailong Jiang, Kuidong Luo, Bin Wang. A new method for early gas kick detection based on the consistencies and differences of bottomhole pressure at two measured points. Journal of Petroleum Science and Engineering, 2019, vol. 176, pp. 1095-1105.

21. Galkin V.I., Ponomareva I.N., Chernykh I.A., Filippov E.V., Chumakov G.N. Methodology for determining bottomhole pressure using multidimensional models. Oil industry, 2019, no. 1, pp. 40-43. In Rus.

22. Dongjae Kam, Jichao Han, Akhil Datta-Gupta. Streamline-based history matching of bottomhole pressure and three-phase production data using a multiscale approach. Journal of Petroleum Science and Engineering, 2017, vol. 154, pp. 217-233.

23. Martyushev D.A., Yurikov A. Evaluation of opening of fractures in the Logovskoye carbonate reservoir, Perm Krai, Russia Petroleum Research, https://doi.org/10.1016/j.ptlrs.2020.11.002

24. Jahanandish J., Salimifard B., Jalalifer H. Predicting bottomhole pressure in vertical multiphase flowing wells using artificial neural networks. Journal of Petroleum Science and Engineering, 2011, vol. 75, Iss. 3-4, pp. 336-342.

25. Martyushev D.A. Rock stress state influence on permeability of carbonate reservoirs. Bulletin of the Tomsk Polytechnic University, Geo Assets Engineering, 2020, vol. 331, Iss. 8, pp. 24-33. In Rus.

26. Rastegaev R.A., Morozov V.V., Melnikov S.I., Idrisova S.A., Milchakov S.V. Conceptual geological modeling as a basis for the development of carbonate deposits on the example of a field in the Middle East region. Georesources, 2018, vol. 20, no. 3, pp. 168-171. In Rus.
27. Mingshui Song Reservoir formation conditions and key technologies for exploration and development in Shengtuo oilfield in Bohai Bay Basin. Petroleum Research, 2020, vol. 5, Iss. 4, pp. 289-303.

28. Popov V.L., Podnebesnykh A.V., Pylnik S.V. Determination and characteristics of the reservoir connectivity coefficient of geological and hydrodynamic models of oil and gas deposits. Bulletin of the Tomsk Polytechnic University. Geo Assets Engineering, 2020, vol. 331, no. 1, pp. 211-221. In Rus.

29. Ermekov R.I., Merkulov V.P., Chernova O.S., Korovin M.O. Especially considering the anisotropy of permeability in the hydrodynamic model. Journal of Mining Institute, 2020, vol. 243, pp. 299-304. In Rus.

30. Abbasov E.M., Agaeva N.A., Kerimova Sh.A. Integral modeling of gas well operation considering the deformability of the reservoir. SOCAR Proceedings, 2019, no. 2, pp. 45-52. In Rus.

31. Huafeng Sun, Sandra Vega, Guo Tao. Analysis of heterogeneity and permeability anisotropy in carbonate rock samples using digital rock physics. Journal of Petroleum Science and Engineering, 2017, vol. 156, pp. 416-429.

32. Xinhui Xie, Hongjiang Lu, Hucheng Deng, Hongzhi Yang, Bailu Teng, Huazhou Andy Li. Characterization of unique natural gas flow in fracture-vuggy carbonate reservoir: a case study on Dengying carbonate reservoir in China. Journal of Petroleum Science and Engineering, 2019, vol. 182, 106243.

33. Rashid F., Glover P.W.J., Lorinczi P., Collier R., Lawrence J. Porosity and permeability of tight carbonate reservoir rocks in the north of Iraq. Journal of Petroleum Science and Engineering, 2015, vol. 133, pp. 147-161.

34. Martyushev D.A. Improving the geological and hydrodynamic model a carbonate oil object by taking into account the permeability anisotropy parameter. Journal of Mining Institute, 2020, vol. 243, Iss. 3, pp. 313-318. In Rus.

35. Hongyan Yu, Zhenliang Wang, Fenggang Wen, Reza Rezaee, Maxim Lebedev, Xiaolong Li, Yihuai Zhang, Stefan Iglauere. Reservoir and lithofacies shale classification based on NMR logging. Petroleum Research, 2020, vol. 5, Iss. 3, pp. 202-209.

36. Chenjun Huang, Geyun Liu, Kaibo Shi, Jinyin Yina, Jinrui Guo, Chongzhi Tao. Hydrocarbon migration in fracture-cave systems of carbonate reservoirs under tectonic stresses: A mechanism study. Petroleum Research, 2020, vol. 5, Iss. 2, pp. 124-130.

Received: 12 April 2021.

\section{Information about the authors}

Dmitriy A. Martyushev, Cand. Sc., associate professor, Department of Oil and Gas Technologies Perm National Research Polytechnic University. 